\title{
Exposé moderne des mathématiques élémentaires: quando uma obra precede sua autora
}

\section{Exposé moderne des mathématiques élémentaires: when a work precedes its author}

Elisabete Zardo Búrigo ${ }^{1}$

\begin{abstract}
Resumo
$\mathrm{O}$ artigo trata da produção do livro Exposé moderne des mathématiques élémentaires, pela autora francesa Lucienne Félix, e de sua recepção, no Brasil, pelos professores integrantes do Grupo de Estudos em Ensino de Matemática (GEEM), criado em São Paulo, em 1961. A partir da interpretação de relatos autobiográficos e de outros documentos, argumenta-se que a apresentação da obra, no Brasil, precedeu a da autora, não apenas no plano cronológico, mas também do ponto de vista do reconhecimento, da legitimidade e da difusão de ideias de inovação do ensino, que participaram da onda internacional conhecida como Movimento da Matemática Moderna. Em suas traduções e edições, o livro percorreu caminhos inesperados para uma obra de professora do ensino secundário que não contava com o apoio do Ministério da Educação francês. No Brasil, sua circulação foi restrita, mas constituiu-se como uma das referências para as proposições do GEEM e para o intercâmbio dos professores com Lucienne Félix, ao longo dos anos 1960.
\end{abstract}

Palavras-chave: Movimento da Matemática Moderna; História da Educação Matemática; Manuais Pedagógicos.

\begin{abstract}
The article deals with the production of the book Exposé moderne des mathématiques élémentaires, by the French author Lucienne Félix, and its reception in Brazil by the members of the Mathematics Teaching Study Group (GEEM), created in São Paulo in 1961. The author argues that the presentation of the work preceded that of the author, not only in the chronological plane, but also from the point of view of the recognition, legitimacy and diffusion of ideas of innovation of teaching, within the international wave known as the Modern Mathematics Movement. In its multiple translations and editions, the book traveled unexpected paths to a work of secondary school teacher that did not count with the support of the French government. In Brazil, its circulation was restricted, but it was one of the references for the legitimization of GEEM itself and for the exchange of teachers with Lucienne Félix, during the 1960s.
\end{abstract}

Keywords: Modern Mathematics Movement; History of Mathematics Education; Pedagogical manuals.

\section{Introdução}

Nos anos 1960, diversos impressos produzidos sob o signo do chamado Movimento da Matemática Moderna, por autores e grupos de diferentes países, circularam no Brasil e foram, também de modos variados, tomados como referência para a produção local de propostas de programas, de cursos de formação de professores e de livros didáticos.

Dentre esses impressos, destacam-se livros didáticos que apresentam propostas

Submetido em: 15/12/2019 - Aceito em: 26/03/2019 - Publicado em: 30/03/2019

${ }^{1}$ Doutora em Educação pela Universidade de São Paulo. Professora da Universidade Federal do Rio Grande do Sul, Brasil. Email: elisabete.burigo@ufrgs.br . 
DOI: https://doi.org/10.20396/zet.v27i0.8654365

tentativamente coerentes de inovação curricular para o ensino de matemática na escola secundária, apoiadas em experimentações. Tal é o caso das coleções produzidas pelo norteamericano School Mathematics Study Group (SMSG), traduzidas e adaptadas para publicação no Brasil por iniciativa do Instituto Brasileiro de Educação, Ciência e Cultura (IBECC), órgão local da Organização das Nações Unidas para a Educação, a Ciência e a Cultura (UNESCO) (Oliveira Filho, 2009; Silva \& Garnica, 2013); também é o caso da coleção Mathématique Moderne de Georges e Frédérique Papy, que inspirou experimentações realizadas no Rio de Janeiro e na Bahia e a produção local de livros (Ferreira da Costa, 2014; Freire, 2014).

Este artigo toma como objeto de investigação a produção, na França, e a recepção, no Brasil - mais precisamente em São Paulo -, de um único livro, o Exposé moderne des mathématiques élémentaires, de Lucienne Félix. Publicado pela primeira vez em 1959, na França, pela editora Dunod, o livro foi então apresentado como material de referência para as classes de mathématiques élémentaires, oferecidas no último ano do ensino secundário francês como transição para estudos universitários nas áreas das chamadas Ciências. Mencionado na publicação Mathématiques nouvelles, da Organização Europeia de Cooperação Econômica (OECE) (1961), o livro foi reeditado na França em 1962 e em 1966, e publicado em seis idiomas, além do francês.

Diferentemente das já mencionadas coleções do SMSG e de Papy, a obra não foi traduzida para o português nem para o espanhol, nem são conhecidos indícios de que tenha inspirado, no Brasil, produções locais assemelhadas ou experimentações em salas de aula. Pela sua presença em algumas bibliotecas universitárias ${ }^{2}$ e por relatos autobiográficos, sabemos, contudo, que circulou e era conhecida pelos professores que fundaram, em 1961, o Grupo de Estudos em Ensino de Matemática (GEEM) de São Paulo. A partir de considerações sobre a produção da obra, sobre alguns elementos da proposta curricular ali apresentada e sobre a presença de Lucienne Félix no Brasil em diferentes momentos dos anos 1960, argumenta-se, neste texto, que o Exposé moderne ${ }^{3}$ cumpriu o interessante e peculiar papel de apresentar aos professores do GEEM sua autora - uma professora francesa do ensino secundário que, para a divulgação de suas ideias, não contava com o prestígio de uma cadeira universitária nem com o apoio de agências governamentais. Esse seria, então, um caso de apresentação do autor pela obra, em sentido inverso ao da representação mais disseminada, de apresentação da obra pelo autor.

Com essa discussão, sob a inspiração da chamada história conectada, procura-se contribuir para compreender a "multiplicidade de formas de contatos, interconexões, circulações" (Douki \& Minard, 2007, p. 11) que caracterizou o Movimento da Matemática Moderna, no plano internacional e também no que diz respeito às suas várias leituras e

\footnotetext{
${ }^{2}$ Notadamente, bibliotecas de diferentes unidades da Universidade de São Paulo e da Pontifícia Universidade Católica de São Paulo.

3 Por Exposé moderne, estaremos sempre nos referindo à obra Exposé moderne des mathématiques élémentaires. Na próxima seção, tomaremos como base, para discussão sobre a obra, exemplar do livro publicado em 1966 pela mesma editora Dunod.
} 
proposições, no Brasil.

\section{Uma obra de iniciação}

Évelyne Barbin (2013) refere-se ao Exposé moderne como uma ouvrage d'initiation ou obra de iniciação, repetindo uma expressão mobilizada pela própria Lucienne Félix, no prefácio do livro ${ }^{4}$ (Félix, 1966, p. VI). Mas qual iniciação?

Em uma versão estrita, a autora poderia estar se referindo à iniciação do leitor aos estudos universitários: "Ao longo de uma apresentação das teorias elementares e dos capítulos que são um desenvolvimento natural dessas teorias, tomar-se-á um primeiro contato com os conceitos, os métodos e os símbolos das Matemáticas superiores” (Félix, 1966, p. V).

Mas Lucienne Félix não se refere apenas à transição a ser vivida, por um leitor até então habituado à linguagem e aos métodos da matemática escolar, elementar, para os estudos em nível mais avançado. O livro também pretende apresentar uma nova abordagem das matemáticas elementares, diferente daquelas usualmente apresentadas nos livros escolares: "Nós nos propomos a estudar a matéria que, tradicionalmente, constitui as matemáticas elementares sob uma forma que prepara os estudos posteriores de matemáticas superiores" [ênfase adicionada] (Félix, 1966, p. VI). Isto é, a autora revela-se empenhada em convencer os leitores de que as matemáticas elementares podem ser apresentadas segundo uma perspectiva consistente com a das matemáticas superiores. Essa abordagem inclui: a adoção do método axiomático, em que um conjunto de resultados é obtido a partir de um pequeno conjunto de axiomas, que podem ser escolhidos; a definição de objetos matemáticos por meio de suas propriedades; a ênfase em resultados genéricos, que independem da natureza dos objetos matemáticos envolvidos.

O livro é organizado em quatro grandes seções: "As estruturas fundamentais", contendo uma breve apresentação da teoria dos conjuntos, um estudo inicial dos números, das funções numéricas, dos espaços métricos euclidianos e da noção de probabilidade; "Aritmética e Álgebra", abrangendo uma construção do conjunto dos números reais e a demonstração de sua não enumerabilidade; "Análise", incluindo estudos sobre continuidade e derivadas de funções numéricas e o corpo dos números complexos; "As Geometrias", abarcando estudo de isometrias, semelhanças, inversões e cônicas, e uma introdução às geometrias não euclidianas.

A apresentação dos números ilustra o esforço de abstrair, da discussão, a natureza dos objetos: "Os elementos de um conjunto são muitas vezes chamados de pontos, porque são considerados indecomponíveis. Quando o conjunto é munido de operações internas, esses elementos são chamados números, por extensão da palavra número que é aplicada aos inteiros naturais" (Félix, 1966, p. 12). Os conjuntos dos números naturais, inteiros, racionais e reais são construídos a partir da escolha de um conjunto de axiomas progressivamente alargado.

\footnotetext{
${ }^{4}$ A edição de 1966 repete o prefácio da edição original e acrescenta um "avertissement de la troisième édition".
} 
DOI: https://doi.org/10.20396/zet.v27i0.8654365

A ideia de classe de equivalência é mobilizada em várias seções: por exemplo, ângulos são apresentados como classes de equivalência de pares ordenados de vetores, a partir de uma definição de congruência entre pares de vetores.

A construção dos objetos matemáticos e dos resultados é entremeada de comentários acerca de preocupações com rigor e coerência. A autora adverte contra abusos de linguagem, como os que identificam números absolutos com números positivos, e assinala que o isomorfismo entre os conjuntos não deve levar à confusão entre objetos que são distintos, porque definidos de modos diversos.

Um propósito explícito do livro é o de "reconstruir sob uma forma matematicamente satisfatória o conjunto dos resultados acumulados ao longo dos estudos elementares, conhecimento ainda impregnado de elementos sensoriais, justificado pelo apelo à experiência física e a uma intuição não analisada do espaço" (Félix, 1966, p. V). Várias passagens são ilustradas por imagens de figuras geométricas e gráficos variados, em um explícito apelo à intuição; o uso desses recursos é justificado pela autora por meio de isomorfismos entre objetos físicos (como flechas) e objetos abstratos (como vetores).

Barbin (2013) refere-se ao Exposé moderne como uma "mistura de gêneros" (p. 129) pois, ao mesmo tempo que é alegadamente endereçado a estudantes e professores do ensino secundário, apresenta uma matemática dos profissionais, dos matemáticos, que não estava prevista nos programas do ensino secundário francês vigentes à época. Quais teriam sido, então, as intenções que moveram Lucienne Félix na escrita do livro? Qual teria sido o público por ela visado?

Em seus escritos autobiográficos, Lucienne Félix atribui a Georges Bouligand o convite para a produção de seu primeiro livro: a obra L'aspect moderne des mathématiques, publicada pela editora Blanchard em 1957, teria sido encomendada como uma introdução à concepção moderna das matemáticas elementares, em atendimento a uma reconhecida curiosidade por parte dos professores (Félix, 2005).

Quanto ao Exposé moderne des mathématiques élémentaires, publicado pela primeira vez em 1959, Lucienne Félix não menciona nenhuma encomenda. Recorda que, ao longo de quatro anos, trabalhou na produção desse que nomeava "meu grande livro", lecionando durante o dia e escrevendo à noite (Félix, 2005). São indícios de que, diferentemente de L'aspect moderne, o Exposé foi, sobretudo, uma iniciativa da própria autora. Uma das chaves para compreender essa empreitada é o que Lucienne Félix (2005) descreve como adesão ao "movimento bourbakista" (p. 84), ao final dos anos 1940.

\section{Uma leitora de Bourbaki}

Lucienne Félix iniciou sua carreira de professora do ensino secundário em 1923, como agrégée de mathématiques. $\mathrm{O}$ título, destacado em sua autobiografia ${ }^{6}$, faz menção ao

\footnotetext{
${ }^{5}$ No original, "mon gros livre" (Félix, 2005, p. 92). Todas as traduções são de responsabilidade da autora.

${ }^{6}$ Réflexions d'une agrégée de mathématiques au XX siècle (Félix, 2005).
} 
DOI: https://doi.org/10.20396/zet.v27i0.8654365

exigente concurso de agrégation que, precedido de estudos oferecidos pelas universidades ou pelas prestigiadas Écoles normales supérieures, habilitava à docência no último ciclo do ensino secundário. Em um tempo em que, na França, a formação e a carreira das mulheres eram apartadas das carreiras dos homens ${ }^{7}$, Lucienne frequentou a École normale supérieure de jeunes filles de Sèvres, onde foi aluna de matemáticos eminentes como Henri Lebesgue, Émile Picard e Émile Borel. Da École, ela diz ter herdado o "espírito de Sèvres", uma expressão difusa que faz referência a uma educação arejada e ampla, incluindo articulações entre a formação literária e uma formação matemática orientada para a curiosidade e a discussão de problemas, sem as pressões para o estrito cumprimento dos programas e para o sucesso no prestigiado concurso destinado aos homens. Nos anos 1920, Sèvres passou a contar também com uma escola secundária anexa, uma École d'Application, ambiente de estágio e de debate sobre a renovação do ensino (Félix, 2005).

No hierarquizado sistema de ensino francês da primeira metade do século XX, o ensino secundário era mais valorizado do que o primário, e o prestígio da atividade docente, no ensino secundário, crescia conforme a proximidade com os estudos universitários e, especialmente, com as grandes écoles. No topo da hierarquia do ensino pré-universitário, estavam as classes préparatoires - de preparação para os concursos de ingresso nas grandes écoles -, oferecidas em um pequeno punhado de liceus. Entre os professores das classes préparatoires eram recrutados os inspetores de ensino, responsáveis pela redação dos programas e das instruções metodológicas e pela vigilância no seu cumprimento, que incluía visitas, observações, orientações e avaliações das aulas dos demais professores.

Após alguns anos como professora em variadas classes de liceus e dez anos como professora assistente de Lebesgue na École normale de Sèvres, Lucienne Félix assumiu, em 1939, uma turma de classes préparatoires em Versailles. Em 1940, foi afastada do serviço público, por ser judia; em agosto de 1944, foi presa no campo de concentração de Drancy, ao norte de Paris. Com o recuo da ocupação nazista, Lucienne Félix foi libertada e retornou à vida ativa em outubro, mas em março de 1945 foi destituída das classes préparatoires, sem processo formal, e sem uma alocação definida (Brasseur, 2011). Em sua autobiografia, ela faz várias menções a perseguições que teria sofrido por parte de inspetores gerais, não apenas por ser mulher e judia, mas por praticar, em Versailles e em outros espaços, um ensino pautado pela discussão dos problemas, e não pelo treinamento para as questões de exame (Félix, 2005).

Em 1946 Lucienne Félix assumiu novo posto no Lycée La Fontaine, instituição de ensino secundário para moças, situado no aristocrático $16^{\text {ème }}$ arrondissement de Paris. Foi encarregada das classes quatrième e troisième (anos finais do primeiro ciclo do secundário) e, a partir de 1949, lecionou também para as recém-criadas classes de mathématiques élémentaires, oferecidas como uma modalidade da série final do secundário - a Terminale -,

\footnotetext{
${ }^{7}$ Segundo Hulin (2002), apenas em 1976 os concursos de agrégation em matemática foram unificados.
} 
DOI: https://doi.org/10.20396/zet.v27i0.8654365

em preparação para o exame de baccalauréat desse ramo (Brasseur, 2011) ${ }^{8}$.

Nessa época, ganhou notoriedade o trabalho do grupo de matemáticos franceses constituído, nos anos 1930, sob o pseudônimo Nicolas Bourbaki. Em 1947, o grupo divulgou o manifesto L'architecture des mathématiques, que advogava a reconstrução do edifício dos resultados matemáticos segundo o método axiomático ${ }^{9}$ e o papel central das estruturas algébricas, de ordem, e dos espaços topológicos nessas então chamadas mathématiques modernes. Um dos objetivos centrais dos bourbakistas era renovar o ensino universitário de matemática na França, o que de fato ocorreria a partir dos anos 1950 (Gispert, 2014).

As primeiras leituras de Bourbaki, segundo os relatos de memória de Lucienne Félix, foram indicadas por um colega norueguês, então orientado pelo bourbakista Laurent Schwartz. O contato com os livros de Álgebra e de Topologia, ao final dos anos 1940, teria sido revelador: o enfoque das relações entre os objetos, características das estruturas matemáticas, propiciava uma visão nova, ampliada e generalizadora dos problemas. Ela menciona, também, uma conferência de Jean Dieudonné, "que esclareceu definitivamente para mim a ação do grupo Bourbaki” (Félix, 2005, p. 82), ao estabelecer uma analogia entre um problema de álgebra e um de topologia. Desde então, ela teria se proposto a missão de adaptar a obra de Bourbaki para a matemática escolar: "Ora, eu não sou uma matemática, mas uma professora de matemática, e me convenci imediatamente de que era possível compartilhar essa luz em todos os níveis de aprendizagem” (Félix, 2005, p. 128).

Lucienne Félix não estava solitária nessa vontade de estender a modernização da matemática até a escola. Nos anos 1950, essa ambição era motivadora de debates e iniciativas que agregavam professores do ensino secundário e superior, de diferentes estabelecimentos, na França e em intercâmbios internacionais (Gispert, 2014). Foi nesse ambiente, e participando do que ela mesma descreve como um "movimento", que Lucienne escreveu o Exposé moderne.

\section{O movimento bourbakista}

A Association des Professeurs des Mathématiques de l'Enseignement Public (APMEP) foi, na França do pós-guerra, o fórum mais ativo na promoção de debates e na proposição da modernização do ensino de matemática na escola secundária (D’Enfert, 2010). Em 1950, constituiu-se no interior da APMEP a comissão Axiomatique et redécouverte, cujo nome faz alusão ao método axiomático propugnado pelos bourbakistas e à "redescoberta", pedagogia proposta pelo inspetor geral Émile Blutel, em que as demonstrações dos teoremas são construídas pelos estudantes, ao invés de serem impostas pelos professores. Marceline

\footnotetext{
${ }^{8}$ Ao final do ensino secundário, os estudantes franceses passam pelo exame de baccalauréat, tendo em vista um diploma e uma nota que será considerada para o ingresso em curso universitário. Diferentes ramos do secundário preparam para diferentes modalidades de baccalauréat. $\mathrm{O}$ ramo mathématiques élémentaires tem origem na reforma do ensino secundário francês, decretada em 1902.

9 Em texto publicado na revista Cahiers Pédagogiques, Dieudonné (1955) descreve a essência do método axiomático como a opção assumida de "raciocinar sobre objetos conhecidos (em geral voluntariamente) de modo incompleto, isto é, por um certo número de suas propriedades, excluindo outras” (p. 179).
} 
DOI: https://doi.org/10.20396/zet.v27i0.8654365

Dionot, antiga professora da École d'Application de Sèvres, foi uma das articuladoras da comissão. Ela também coordenava o Groupe d'étude des professeurs de mathématiques que se reunia, desde o final dos anos 1940, no Centre International d'Études Pédagogiques (CIEP) de Sèvres. O CIEP era, então, um polo promotor das classes nouvelles, pelas quais se experimentava a renovação do ensino secundário francês, buscando uma formação integral, baseada na valorização dos métodos ativos e do estudo do meio (Savoye, 2010).

Lucienne Félix participava ativamente dos dois grupos, por convite de Marceline Dionot, e defendia a colaboração entre ambos, ao mesmo tempo que explicitava sua visão de hierarquia intelectual ${ }^{10}$ :

Permito-me sugerir que em minha opinião esse grupo [de Sèvres], que estuda as crianças que frequentam o nosso ensino, deveria fazer um movimento em direção ao grupo que vem do alto, da ciência matemática, para descer até o aluno. Se nós nos limitarmos a observar as dificuldades de ensinar o que usualmente ensinamos, da maneira habitual, como se fosse a intangível verdade matemática, as pesquisas correm o risco, creio, de não serem verdadeiramente fecundas. O conhecimento real da criança, que é a riqueza deste grupo, lhe permitirá estudar o conjunto da questão segundo o grau de maturidade dos alunos, sem sacrificar aqueles que jamais serão matemáticos, mas sem negligenciar a escalada na direção do pensamento matemático (Félix, 1953, p. 59).

Lucienne Félix também participou das reuniões internacionais que dariam origem à Comission Internationale pour l'Étude et l'Amélioration de l'Enseignement des Mathématiques (CIEAEM). Em abril de 1950, por intermédio de Edmée Hatinguais, então diretora do CIEP, ela foi convidada a participar de um encontro organizado por Caleb Gattegno, professor da Universidade de Londres, com o tema "Relações entre os programas de matemática das escolas secundárias e o desenvolvimento das capacidades intelectuais do adolescente" (Bernet \& Jaquet, 1998; Félix, 2005). O seminário reuniu 13 intelectuais e especialistas de diferentes países. No ano seguinte, os encontros se repetiram; a constituição da CIEAEM ocorreu no quarto evento, realizado em abril de 1952, em La Rochette par Melun, nos arredores de Paris.

Ao longo dos anos 1950, a CIEAEM se ampliou, com novas adesões e o reconhecimento por parte de organismos oficiais como a Organização das Nações Unidas para a Educação, a Ciência e a Cultura (UNESCO) e a OECE. A influência do grupo Bourbaki nos debates da CIEAEM foi notável (Gispert, 2010). O projeto de constituição da Comissão menciona o estudo da obra do grupo como uma de suas atividades. O encontro de fundação, em 1952, teve como tema "Estruturas matemáticas e estruturas mentais". O bourbakista Jean Dieudonné participou das reuniões e é, inclusive, autor de um capítulo do livro L'Enseignement des mathématiques, organizado e publicado em 1955 pela CIEAEM (Bernet \& Jaquet, 1998). De 1952 a 1963, a Comission foi presidida pelo matemático Gustave Choquet, que, sem se considerar bourbakista - inclusive opondo-se a algumas teses

\footnotetext{
${ }^{10}$ Pela animosidade que marcou as relações de Lucienne Félix com a inspetoria geral do ensino secundário, pode-se pensar que a menção aos matemáticos como representantes do "alto" pretende enfatizar a hierarquia que ela reconhece como legítima, a dos pensadores, em oposição à hierarquia burocrática do Ministério da Educação.
} 
DOI: https://doi.org/10.20396/zet.v27i0.8654365

de Dieudonné -, foi protagonista da modernização do ensino de matemática na Universidade de Paris, e interlocutor da APMEP (Gispert, 2010).

Ativa em todas essas instâncias, Lucienne Félix publicou artigos, resenhas de livros e outros comentários no Bulletin de l'APMEP e nos Cahiers Pédagogiques pour l'Enseignement du Second Degré, um periódico dedicado à divulgação dos projetos de renovação do ensino secundário. Em 1955, ela foi encarregada de conduzir uma enquete sobre "As matemáticas modernas e o ensino".

Três trechos de respostas ao questionário são ilustrativos dos debates então correntes.

Jean Dieudonné (1955) exalta "a economia de pensamento permitida pela abstração e pela generalidade extrema das noções matemáticas modernas, depuradas de todas as considerações contingentes que possam ser obstáculo à boa compreensão dos raciocínios" (p. 178).

Willy Servais (1955), professor secundário na Bélgica e uma das figuras centrais da CIEAEM, declara sua simpatia entusiasta pelo movimento modernizador:

Quando captamos a intenção da matemática moderna e estudamos a sua organização interna, experimentamos a alegria de compreender melhor o que havíamos simplesmente acreditado compreender até então. Sentimo-nos tornar conscientes das matemáticas. Como então não tentar transmitir essa tomada de consciência? Como escapar ao dever de fazê-lo? (p. 168)

Jacques Siros (1955), professor do Liceu Lakanal, na cidade de Sceaux, também advoga a modernização do ensino, ao mesmo tempo que reclama por uma tradução da obra de Bourbaki que pudesse, então, orientar a ação dos professores:

Nós nos dizemos: "Aprendamos Bourbaki pacientemente, e fiquemos satisfeitos se fizermos apenas três páginas por semana". Eu reconheço que esse é, no fundo, o verdadeiro método. Mas, por esse meio, eu não estarei em condições de sintonizar meu ensino com a nova tonalidade em menos de algumas dezenas de anos! É preciso encontrar outro caminho. Eu sei que não há uma voie royale, mas ao menos que alguém me dê matemáticas modernas, em algum tipo de segunda mão, que me dê sugestões, exemplos de questões mais ou menos clássicas, mas tratadas segundo um ponto de vista novo; assim, não serei o único a pesquisar. (p. 167)

As declarações recolhidas por Lucienne Félix dão pistas sobre uma das condições que possibilitou a produção do Exposé moderne: a legitimidade atribuída às propostas de modernização, por parte de matemáticos, professores e revistas pedagógicas da época, na França. A resposta de Dieudonné é um testemunho de seu engajamento no debate; também realizou conferências e publicou, à época, artigos no Bulletin d'APMEP. Se os bourbakistas não pretendiam, de início, propor uma reforma do ensino secundário, certamente encorajaram os professores a empreendê-la. A resposta de Siros, em particular, é indicativa de uma segunda condição para a produção do livro: a existência de um provável público interessado em um texto didático que desbordasse o programa vigente. 


\section{Uma obra sancionada}

Nos anos 1950, Lucienne acumulou seus encargos no Lycée La Fontaine com atividades de interrogateur dos alunos do curso introdutório de Mathématiques Générales da Universidade de Paris, em colaboração com Laurent Schwartz, preparando os alunos e participando das bancas de exame oral (Félix, 2005). É provável que as reflexões e as experimentações realizadas nesses dois ambientes tenham constituído o material de base do Exposé moderne, que, conforme mencionado na introdução, era declaradamente dirigido aos professores e aos estudantes das classes de mathématiques élémentaires, dedicadas à preparação e à transição para o ensino superior.

Sendo ela uma militante bourbakista, pode-se também inverter o raciocínio, e pensar que a escrita de um livro para a última classe do liceu foi o caminho encontrado para produzir uma obra abrangente, que reunisse os vários tópicos e temas da Matemática, pois revisar os resultados e os conceitos fundamentais, sob uma perspectiva mais rigorosa e avançada, era tarefa e finalidade das mathématiques élémentaires. O Exposé apresentou-se, então, como uma primeira tentativa de reproduzir, no ensino secundário, a mesma perspectiva globalizante e modernizadora que orientava o grupo Bourbaki na produção de sua obra.

As conexões construídas ao longo dos anos 1950, no CIEP, na CIEAEM e na APMEP, contribuíram para viabilizar a publicação da obra, em 1959, como item da prestigiada Collection Universitaire de Mathématiques da editora Dunod. Em sua autobiografia, Lucienne agradece ao matemático André Lichnerowicz, então diretor da coleção, pelo acolhimento (Félix, 2005).

A obra foi comentada por Gilbert Walusinski, também militante modernizador e então secretário-geral da APMEP. Em um artigo nos Cahiers Pédagogiques, ele elogia o espírito modernizador do Exposé:

A obra de Mlle. Félix é destinada aos alunos da classe terminale. Ela lhes permite estudar todo o programa atual, mas com uma importante economia de recursos representada pela introdução declarada das noções fundamentais de conjuntos, grupos e estrutura.... Por outro lado, há alguns acréscimos pelos quais certamente não se poderá censurar nossa colega: não é escandaloso deixar que os alunos ignorem os números complexos? [...] O que conta é o espírito resolutamente modernista, quanto à linguagem, quanto ao simbolismo, quanto ao modo de encadear as ideias principais do curso. E tudo isso, sem desprezar as exigências pedagógicas, mas com a preocupação (que se poderá até mesmo julgar excessiva) de preparar a introdução das noções novas por vias que parecem naturais. (Walusinski, 1960a, p. 83)

O Bulletin de l'APMEP do mês de março de 1960 divulga uma breve resenha do livro, também da autoria de Walusinski (1960b). O texto inclui um comentário irônico sobre as resistências à modernização, possivelmente endereçado à inspetoria do ensino secundário:

Fala-se muito de modernizar os programas de Matemática. Nas discussões apaixonadas sobre esse tema, objeta-se que, antes de preconizar os novos programas, seria necessário que professores e alunos pudessem dispor de novos manuais. Mas os audaciosos que escrevem tais livros devem estar conscientes do que os aguarda: serão recriminados por não seguirem os programas tais quais são.... Suas tentativas poderão 
DOI: https://doi.org/10.20396/zet.v27i0.8654365

expô-los a muitos ataques mais ou menos honestos (o que já se viu ocorrer). Aqui, entre colegas trabalhando em comum pela renovação dos métodos e dos programas, devemos render homenagem a esses pioneiros corajosos. (p. 299)

A hostilidade das autoridades educacionais ao livro, sugerida por Walusinski, é confirmada em publicação da CIEAEM: "Na França, a Comission (CIEAEM) não pôde influir diretamente sobre as decisões oficiais relativas aos programas. Os livros de Lucienne Félix apresentavam suas concepções pessoais. Tiveram, sobretudo, influência no exterior, pelas traduções" (Félix, 1986, p. 98).

Como teria se dado a circulação internacional dos livros, sem o apoio do Ministério da Educação francês? Uma das vias foi constituída pelos encontros da CIEAEM, nos quais Lucienne permaneceu ativa. Para o alcance de um público mais amplo, foi importante a publicação da Organização Europeia de Cooperação Económica (OECE) (1961), resultante do notável seminário realizado em Royaumont, nos arredores de Paris, de 23 de novembro a 4 de dezembro de 1959.

A OECE, criada em 1947 para administrar o Plano Marshall de reconstrução da Europa Ocidental no pós-guerra, tinha como uma de suas metas, a partir de 1958, tornar mais eficiente o ensino de matemática e de ciências (Schubring, 2014). Os objetivos declarados do evento de Royaumont eram os de fazer um apanhado das propostas modernizadoras, discutir os objetivos e as mudanças desejáveis no ensino, e as medidas necessárias para a modernização, em termos de materiais, métodos de ensino e formação de professores (OECE, 1961). O Seminário foi presidido por Marshall Stone, presidente da International Commission on Mathematical Instruction (ICMI), e contou com a participação de representantes dos países membros e 13 palestrantes convidados. Gustave Choquet, Jean Dieudonné e Willy Servais, figuras eminentes da CIEAEM, eram alguns desses palestrantes (OECE, 1961).

A França foi representada no evento pelo Inspetor Geral do Ensino Secundário, Pierre Theron, e pelo professor do ensino secundário André Huisman. Lucienne Félix e Emma Castelnuovo foram as únicas mulheres participantes do evento - Lucienne, como conferencista, e Emma, como uma das representantes da Itália.

Um relatório do Seminário compilado por Howard Fehr foi publicado em 1961 sob o título de Mathématiques nouvelles ${ }^{11}$ (OECE, 1961). O livro não inclui os textos das palestras; pelos arquivos do evento, sabe-se que a palestra de Lucienne Félix foi intitulada "Ensino de matemática para crianças com dom para matemática" (Schubring, 2014). Por outro lado, o texto de Fehr menciona que ela "mostrou, por exemplos, como é possível, entre 11 e 14 anos, envolver o conjunto dos alunos em uma atividade criativa, expondo-lhes os conceitos, o vocabulário técnico, os símbolos e as fórmulas de álgebra" (OECE, 1961, p. 79).

A publicação da OECE, de ampla circulação internacional, registra, portanto, a presença de Lucienne Félix nesse evento que ela, curiosamente, não menciona em suas memórias. Mais relevante, para esta discussão, é o registro que a publicação faz de seus dois

\footnotetext{
${ }^{11}$ Publicado também em inglês com o título New thinking in school mathematics.
} 
DOI: https://doi.org/10.20396/zet.v27i0.8654365

primeiros livros, os já mencionados L'aspect moderne des mathématiques e Exposé moderne des mathématiques élémentaires, em uma lista de textos didáticos que poderiam ser tomados como referência nos processos de modernização (OECE, 1961, p. 264).

A partir de 1961, multiplicaram-se as referências ao Exposé moderne em periódicos científicos e revistas pedagógicas de diferentes países. O livro foi reeditado na França, em 1962 e em 1966, quando o programa das mathématiques élémentaires já fora reformulado. Foi também traduzido e publicado em alemão, russo, grego, turco, romeno e polonês. Nos anos 1960, Lucienne publicou um amplo repertório de livros didáticos, para diferentes etapas de ensino e, inclusive, para crianças pequenas (Félix, 2005).

\section{Lucienne Félix no Brasil}

Lucienne Félix relata vários convites para cursos e palestras no exterior, a partir de 1960. A primeira vinda ao Brasil ocorreu em 1962, como integrante de uma missão pedagógica francesa, coordenada pelo CIEP de Sèvres, incumbida de ministrar cursos para professores secundários nas cidades de Brasília, Rio de Janeiro e São Paulo. Edmée Hatinguais, diretora do CIEP e integrante da missão, convidou Lucienne Félix para substituir, no último momento, um dos membros da missão, impedido de viajar. Essa participação, segundo Lucienne, não foi apoiada pelo Ministério da Educação francês, que, apesar de comunicação prévia, registrou como falta sua ausência no último dia de aulas do semestre letivo, decorrente da viagem (Félix, 1986, 2005).

René Haby (2008), outro integrante da missão, registra a participação de Lucienne Félix como

professora de matemática, que instigava o desenvolvimento das matemáticas modernas, pouco conhecidas na França, enquanto na Bélgica já haviam gerado publicações, e mesmo manuais. Os brasileiros estavam a par disso e muito interessados pela novidade que as matemáticas modernas representavam. (p. 36)

O depoimento de René Haby sugere, então, que a presença de Lucienne Félix, mais do que uma improvisação, teria correspondido a uma demanda do GEEM. Lucilia Bechara confirmou, em depoimento oral à autora ${ }^{12}$, que o Grupo já conhecia os livros e trabalhos de Lucienne e que havia muita curiosidade sobre sua figura, que ela descreveu como uma "senhora parisiense", "de uma certa formalidade" e "pensamento revolucionário"13.

Em relatório à UNESCO, antes da missão, Osvaldo Sangiorgi (1962), fundador e presidente do GEEM já mencionava, entre as diretrizes de ação do Grupo, o "uso conveniente dos novos conceitos de Lucienne Félix sobre a unidade no ensino de matemática, de acordo com os padrões brasileiros" (Anexo, p. 3).

\footnotetext{
${ }^{12}$ Durante conversa por Skype em 23 de junho de 2011.

${ }^{13}$ Cabe registrar que o tratamento Mlle. Félix, então comum na França, denotava ao mesmo tempo que era mulher, e solteira.
} 
DOI: https://doi.org/10.20396/zet.v27i0.8654365

No Arquivo Pessoal Osvaldo Sangiorgi (APOS) ${ }^{14}$, consta um atestado de que Osvaldo Sangiorgi frequentou o curso "Princípios e métodos da nova pedagogia", ministrado pelos professores da Missão Pedagógica Francesa, de $1^{\circ}$ a 25 de agosto de 1962. Também consta um agradecimento a Sangiorgi, por ceder livros de sua autoria para serem enviados à França, em preparação à Missão Pedagógica Francesa ${ }^{15}$.

O primeiro livro do GEEM, destinado aos professores, foi publicado em setembro de 1962, logo após a realização do curso. Na introdução ao livro ${ }^{16}$, Sangiorgi (1965a) faz menção a Lucienne Félix como uma das referências para o trabalho do Grupo:

Conjunto e estrutura são os conceitos que permitirão ao aluno, desde o curso primário, com muito menos esforço do que é dispendido atualmente, compreender a unidade existente na interpretação de fatos que constituem não só o que é ensinado pela Matemática propriamente dita, através de relações que guardam e que não têm sido reveladas. Quem expôs tais relações entre nós, durante o último mês de agosto, foi a ilustre matemática e pedagoga francesa Lucienne Félix que, a convite do GEEM (Grupo de Estudos do Ensino de Matemática), sob o patrocínio da Secretaria da Educação de São Paulo, realizou uma série de interessantes palestras destinadas a professores primários e secundários, sobre aspectos da Matemática Moderna nas Escolas Primária e Secundária. (pp. 2-3)

A introdução menciona obras dedicadas à modernização do ensino de matemática, recentemente publicadas em países europeus ou nos Estados Unidos. Dentre as publicações francesas, destaca o Exposé e o livro Mathématiques modernes $\cap$ Enseignement élémentaire, de Lucienne Félix.

No capítulo "Sistemas matemáticos e estruturas" do mesmo livro, Sangiorgi (1965b) reproduz, com poucas alterações - além da tradução para o português -, um enunciado da introdução do $\operatorname{Exposé}^{17}$ :

Preocupando-se, então, a matemática atual, muito menos com a natureza dos elementos que estuda (números, polinômios, pontos, vetores, etc...) e muito mais com o tipo de estrutura que caracteriza as relações existentes entre esses elementos - que aparentemente pareciam não estarem subordinados a relação alguma - é fundamental que a Escola Secundária de hoje, sem mais perda de precioso tempo, transmita aos seus jovens alunos as verdadeiras mensagens de que é portadora a Matemática contemporânea. (p. 103)

Esse trecho e a inclusão do Exposé entre as referências bibliográficas do capítulo são evidências de que Sangiorgi era um leitor da obra - ou, ao menos, de suas páginas iniciais. Mais ainda, o texto indica que ele assumiu, como seus, os enunciados do prefácio acerca da

${ }^{14} \mathrm{O}$ atestado consta como item APOS T 22431 do arquivo, que está sob a guarda do GHEMAT-Brasil. Foi fornecido pelo Departamento de Educação do Estado de São Paulo e assinado por Alcides Akiau, Coordenador das Classes Experimentais, e pelos membros da missão - Lucienne Félix, René Haby e Jacques Quignard.

15 A carta consta como item APOS T 21772 do APOS. É datada de maio de 1961 e assinada por Luís Contier, Diretor do Serviço de Medidas e Pesquisas Educacionais do Departamento de Educação de São Paulo.

${ }^{16}$ Os extratos aqui citados, afora a paginação, são idênticos aos da edição de 1962.

17 "Les mathématiques modernes se préoccupent moins des objets de l'étude que de la structure des relations entre ces objets ....." (Félix, 1966, p. 1). 
DOI: https://doi.org/10.20396/zet.v27i0.8654365

centralidade das estruturas na matemática moderna. Ele introduz um sutil, mas importante, deslocamento, quando se refere à Escola Secundária, pois enquanto Lucienne Félix se dirigia ao grupo muito especial de concluintes do secundário interessados na matemática universitária, ele quer dialogar com professores do ginásio - portanto, da primeira etapa do secundário -, e com seus formadores, professores universitários.

Em agosto de 1965, Lucienne Félix retornou ao Brasil a convite do GEEM. No final de agosto, proferiu, na cidade de São Paulo, um ciclo de palestras, com a presença de algumas centenas de professores. Visitou escolas, como o Ginásio Vocacional do Brooklin, na qual se desenvolvia uma experiência de ensino da geometria por transformações inspirado por seus trabalhos. Também realizou palestras em Porto Alegre, Salvador e Recife. Em 1968, já aposentada, fez sua última viagem pela América Latina e sua última passagem pelo Brasil (Búrigo, 2015; Félix, 2005).

D’Ambrosio (2017), em seu estudo pioneiro sobre o Movimento da Matemática Moderna no Brasil, conclui que "as ideias de maior impacto sobre o currículo brasileiro foram as do School Mathematics Study Group (SMSG), Georges e Frédérique Papy, Zoltán Dienes, Lucienne Félix e Caleb Gattegno” (p. 176).

\section{Comentários finais}

O Movimento da Matemática Moderna, nos anos 1960, teve como um de seus traços notáveis um intenso intercâmbio internacional. Professores brasileiros participaram ativamente desse processo, buscando materiais e debates, lendo, traduzindo e interpretando esses materiais de modos variados.

Um estudo sistemático das ressonâncias da obra e das passagens de Lucienne Félix pelo Brasil ainda está por ser realizado; do mesmo modo, estão por serem investigadas as conexões entre a iniciativa das Classes Experimentais e o Movimento da Matemática Moderna.

Argumentamos, a partir dos registros e das reflexões apresentados neste artigo, que esse é um caso interessante de ser estudado, como uma evidência de que as ideias modernizadoras não circularam apenas a partir da iniciativa das grandes agências internacionais ou norte-americanas.

A OECE cumpriu um papel importante na divulgação internacional da obra de Lucienne Félix, favorecendo uma circulação provavelmente indesejada pela cúpula do Ministério da Educação francês. Mas, para que Lucienne fosse aceita em um espaço de negociação seletivo e notadamente masculino, como o Seminário de Royaumont, foi relevante seu engajamento nos espaços militantes da APMEP e da CIEAEM.

Não podemos afirmar que o Exposé tenha sido lido, no Brasil, antes da chegada de Lucienne Félix, em agosto de 1962. Mas sabemos que a recepção a Lucienne Félix foi preparada a partir da notícia da existência e do reconhecimento do livro como uma contribuição importante para o movimento modernizador. 
DOI: https://doi.org/10.20396/zet.v27i0.8654365

A obra, à qual ela dedicou anos de sua vida, pode ser então considerada uma "obra de iniciação" também neste sentido: iniciação ao conhecimento de uma autora, professora secundária, militante bourbakista e, conforme as lembranças de Lucilia Bechara, "uma fonte inspiradora".

De caráter abrangente e avançado, o livro não poderia ser traduzido ou adaptado para o uso nesta ou naquela série do ensino secundário: mas constituiu-se, para os professores do GEEM, em referência para a postulação da possibilidade de modernização do ensino de matemática no secundário, a partir das noções fundamentais de conjunto e estrutura, como propunham os bourbakistas.

\section{Agradecimentos}

Agradeço à CAPES, pelo apoio ao estágio pós-doutoral realizado no Service d'histoire de l'éducation em 2011, em Paris; a Renaud d'Enfert, pelo acolhimento e pelo intercâmbio; a Wagner Rodrigues Valente pela oportunidade de participação em projeto CAPESCOFECUB.

\section{Referências}

Barbin, É. (2013). Le genre “ouvrage d'initiation”: l'Exposé moderne des mathématiques élémentaires de Lucienne Félix. In E. Barbin, \& M. Moyon (Eds.), Les ouvrages de mathématiques dans l'Histoire. Entre recherche, enseignement et culture (pp. 117-129). Limoges: Pulim.

Bernet, Th., \& Jaquet, F. (1998). La CIEAEM au travers de ses 50 premières rencontres. Neuchâtel: CIEAEM.

Brasseur, R. (2011). Quelques scientifiques ayant enseigné en classe préparatoire aux grandes écoles. Bulletin de l'Union des Professeurs de Spéciales, 236, 20-27.

Búrigo, E. Z. (2015). Lucienne Félix and Osvaldo Sangiorgi: Interchanges between two Bourbakist militants in the 1960s. In K. Bjarnadóttir, F. Furinghetti, J. Prytz \& G. Schubring (Eds.), "Dig where you stand" 3. Proceedings of the third International Conference on the History of Mathematics Education (pp. 93-107). Uppsala University.

D’Ambrosio, B. S. (2017). Dinâmica e as consequências do Movimento da Matemática Moderna na Educação Matemática do Brasil. Campinas: Mercado de Letras.

D’Enfert, R. (2010). Matemáticas modernas e métodos ativos: as ambições reformadoras dos professores de matemáticas do secundário na Quarta República Francesa (1946-1958). História da Educação, 14(32), 7-30.

Dieudonné, J. (1955). Réponse de M. Dieudonné. Cahiers Pédagogiques pour l'Enseignement du Second Degré, 11(3), p. 178-179.

Douki, C., \& Minard, P. (2007). Histoire globale, histoires connectées: un changement d'échelle historiographique? Revue d'Histoire Moderne et Contemporaine, 54(4bis), 721.

Félix, L. (1953). Les groupes au travail. Bulletin de l'APMEP, 154, 57-61.

Félix, L. (1966). Exposé moderne des mathématiques élémentaires. Paris: Dunod. 
DOI: https://doi.org/10.20396/zet.v27i0.8654365

Félix, L. (1986). Aperçu historique sur la Commission internationale pour l'étude et l'amélioration de l'enseignement mathématique (CIEAEM). Bordeaux: IREM de Bordeaux.

Félix, L. (2005). Refléxions d'une agrégée de mathématiques. Paris: L'Harmattan.

Ferreira da Costa, L. M. (2014). O movimento da matemática moderna no Brasil: o caso do Colégio de São Bento do Rio de Janeiro. Dissertação de Mestrado em Ensino de Matemática. Universidade Federal do Rio de Janeiro, Rio de Janeiro. Retirado em 5 de dezembro, 2018, de http://www.pg.im.ufrj.br/pemat/61\%20Leticia\%20Costa.pdf.

Freire, I. A. A. (2014). Ensino de Matemática: iniciativas inovadoras no Centro de Ensino de Ciências da Bahia (1965-1969). Dissertação de Mestrado em Ensino, Filosofia e História das Ciências. Universidade Federal da Bahia, Salvador. Retirado em 5 de dezembro, 2018, de https://repositorio.ufba.br/ri/bitstream/ri/16023/1/In\%C3\%AAs\%20Ang\%C3 $\%$ A9lica\%20Andrade\%20Freire.pdf.

Gispert, H. (2010). Rénover l'enseignement des mathématiques, la dynamique internationale des années 1950. In R. d'Enfert, \& P. Kahn (Eds.), En attendant la réforme. Disciplines scolaires et politiques éducatives sous la IVe République (pp. 131-143) Grenoble: PUG.

Gispert, H. (2014). Mathematics education in France: 1800-1980. In A. Karp, \& G. Schubring (Eds.), Handbook on the History of Mathematics Education (pp. 229-240). New York: Springer.

Haby, R. (2008). René Haby par lui-même: un engagement pour la jeunesse, 1919-2003. Lyon: INRP-SHE.

Hulin, N. (2002). Les mathématiques et l'enseignement féminin en France. Quelques jalons pour un siècle d'histoire. Bulletin de l'Union des Professeurs de Spéciales, 197, 12-17.

OECE (1961). Mathématiques nouvelles. Paris: OECE.

Oliveira Filho, F. (2009). O School Mathematics Study Group e o Movimento da Matemática Moderna no Brasil. Dissertação de Mestrado em Educação Matemática. Universidade Bandeirante de São Paulo, São Paulo.

Sangiorgi, O. (1962). The present status of mathematics teaching in secondary schools in Argentina, Brazil, Chile, Colombia, Costa Rica, Peru, Uruguay and Venezuela. Annex 1: An Account of Developments in Mathematics Teaching in Schools in Brazil. Letter to UNESCO, Paris, Mar. 5. APOS I 3 1278. GHEMAT Arquives.

Sangiorgi, O. (1965a). Introdução da matemática moderna no ensino secundário. In GEEM (Ed.), Matemática moderna para o ensino secundário (pp. 1-14). São Paulo: IBECC.

Sangiorgi, O. (1965b). Sistemas matemáticos e estruturas. In GEEM (Ed.), Matemática moderna para o ensino secundário (pp. 101-140). São Paulo: IBECC.

Savoye, A. (2010). Réforme pédagogique, réforme disciplinaire: l'expérience des Classes nouvelles dans l'enseignement du second degré (1945-1952). In R. d'Enfert, \& P. Kahn (Eds.), En attendant la réforme. Disciplines scolaires et politiques éducatives sous la IVe République (pp. 51-64) Grenoble: PUG.

Schubring, G. (2014). The Road Not Taken-The Failure of Experimental Pedagogy at the Royaumont Seminar 1959. JMD - Journal für Mathematik-Didaktik, 35, 159-171. 
DOI: https://doi.org/10.20396/zet.v27i0.8654365

Servais, W. (1955). Réponse de M. Servais. Cahiers Pédagogiques pour l'Enseignement du Second Degré, 11(3), p. 167-169.

Silva, T. T. P., \& Garnica, A. V. M. (2013). A coleção Matemática - Curso Ginasial, do SMSG: uma análise. Amazonia - Revista de Educação em Ciências e Matemática, 9(18), $51-74$.

Siros, J. (1955). Réponse de M. Siros. Cahiers Pédagogiques pour l'Enseignement du Second Degré, 11(3), p. 166-167.

Walusinski, G. (1960a). Les mathématiques et le mouvement. Cahiers Pédagogiques, 15(21), 81-84.

Walusinski, G. (1960b). Les mathématiques modernes et l'enseignement. Bulletin de l'APMEP, 206, 299-300. 